\title{
Mapping Vessel Path of Marine Traffic Density of Port Klang, Malaysia using Automatic Identification System (AIS) Data
}

\author{
Masnawi Mustaffa ${ }^{1}$, Noor Hasnita Ahmat ${ }^{2}$, Shaharudin Ahmad ${ }^{3}$ \\ ${ }^{1}$ Office of Information Technology, Universiti Teknologi MARA, Shah Alam 40450, Malaysia \\ ${ }^{2}$ Faculty of Applied Sciences, Universiti Teknologi MARA, Shah Alam 40450, Malaysia \\ ${ }^{3}$ Office of Information Technology, Universiti Teknologi MARA, Shah Alam 40450, Malaysia
}

\begin{abstract}
The Automatic Identification System (AIS) technology is a system that enables a vessel to get information about encountered vessel such as their position, course, speed and others automatically by very high frequency (VHF) radio transmission. This technology has been widely applied in maritime industry to contribute the improvement of marine traffic control and safety. This project is interested to analyse the AIS data collected in order to examines the movements of vessels that transit at Port Klang and Strait of Malacca by mapping the vessels path based on its position (latitude and longitude). The mappings are then investigate and evaluate to visualise the flow of vessel traffic density using the AIS system
\end{abstract}

Keywords: AIS, Vessel Path, Traffic Density, Port Klang, Navigation

\section{Introduction}

Port Klang is Malaysia's busiest shipping port, situated on the West coast of the Malaysian peninsular, due west of the nation's capital Kuala Lumpur at the North end of the Strait of Malacca. The port is linked with other parts of the country by a network of road and rail connections. Port Klang is located about $70 \mathrm{~km}$ from the Kuala Lumpur International Airport (KLIA). It is served by three major gateways called North Port, South Port (South point) and Westports. There are 18 berths in North Port, 8 in South Port and 23 in Westport. The development and growth in port and shipping industries is effected the economy of Malaysia. Over the past 8 years, Port Klang keeps increasing the capacity of cargo and vessel. In 2005 the number of cargo and vessel in Port Klang are $109,658,732$ and 15050 respectively and this number keep increase dramatically until 2013 with cargo and vessel statistic are 200,278,901 and 16703 respectively.(Port Klang Authority's Official Portal, 2015)

The Strait of Malacca and Singapore is also one of the most important shipping channels in the world. It is the shortest shipping route from the Indian Ocean to the Pacific Ocean, linking major economies such as European Union, Middle East, India, China, Japan, South Korea, and others. Since the Strait is vital to the global economy and represents a narrow, shallow, and busy shipping chokepoint, the navigational safety of vessels through the Strait has attracted great attentions from the maritime authorities (e.g. Maritime and Port Authority of Singapore) and other relevant stakeholder such as shippers, carriers. (Xiaobo Qua, 2011)

The Strait of Malacca and Singapore are geographically important and are used as a gateway for many commercial vessels. More than 70,000 vessels traverse the strait per year from year 2006 to 2010 . The high vessel traffic coupled with the narrowness of the Strait is existing navigational hazards. Monitoring of vessel traffic is an important application for safe navigation of the strait. (Masanori Watagawa, 2010)

The scope of this work is to the collect and analyze the data receive by AIS receiver. All the data will be collected only in specific period of time for example one week due to the very high volume of data and based on the data; the mapping vessel path of traffic density is done.

\section{Automatic Identification System}

Since 2002 new ships and later all larger sea going vessels (4300GT) and all passenger vessels are required to carry an Automatic Identification System (AIS) onboard. Through dedicated VHF frequencies, AIS information is transmitted between vessels, from vessels to shore, or vice versa. In simple terms, AIS is a technology to make ships "visible" to each other. As an aid to collision avoidance, it records the information of ship behavior, including the effects of human action and ship maneuverability. The information includes the vessel's name, its particulars, ship type, registration numbers, and destination as well as the vessel's position, speed, and heading. Because the data are transmitted at frequent intervals of approximately 3 to $10 \mathrm{~s}$, some important parameters for collision avoidance can be easily obtained, e.g. the closest point of approach (CPA) and time to closest point of approach (TCPA) between own ship (OS) and any desired target ship (TS).CPA is the distance of the closest point of approach, which is one of the most widely used indicators in collision avoidance. (Jun Min Mou, 2010)

The success of a collision avoidance maneuver can be assessed if CPA is larger than a certain value, for example 2 nautical miles $(\mathrm{nm})$. Otherwise, if CPA is zero and no actions have been taken, the 2 ships will definitely collide with each 


\section{International Journal of Science and Research (IJSR) \\ ISSN (Online): 2319-7064}

Index Copernicus Value (2013): 6.14 | Impact Factor (2014): 5.611

other. Given any two ships (relative) positions, (relative) speeds and (relative) courses, which can be precisely provided by AIS, the tracks of both ships can be estimated. In practice, any collision-involved ship can increase the value of CPA by altering the course or changing the speed for anticollision. Correspondingly, the value of TCPA will change to achieve a safe passage. (Jun Min Mou, 2010)

AIS technology allows the display of information previously only available to modern Vessel Traffic Service (VTS) centers and provides much clearer information allowing mariners to more accurately identify and contact any vessel within VHF range. AIS signals are broadly classified as 'Class A' and 'Class B', where AIS-A is carried by international voyaging ships with gross tonnage (GT) of 300 or more tonnes, and all passenger ships regardless of size. AIS-B is carried by smaller vessels and is aimed at smaller commercial vessels, the fishing sector and recreational vessel users. There are currently 27 different AIS message types which are used in combination to provide AIS-A and AIS-B services. The most commonly used data from AIS messages is the position of a vessel at any given time which is combined with voyage information about the vessel's trip. Position reports are broadcast very frequently (between 2 to 10 seconds, depending on the vessels speed, or every 3 minutes if at anchor) whilst static and voyage related reports are sent every 6 minutes. Other types of messages include search and rescue transmissions, Aid to Navigation (buoys, lights and beacons) and Base Stations which provide meteorological, hydrological and navigation safety information.(Marine Management Organisation MMO, 2014)

According to MMO, UK, (2014) AIS is a relatively new technology for which long-term records are infrequently kept due to the amount of physical disc space needed to store the transmitted messages. For the UK, the most robust data source is the Maritime and Coastguard Agency (MCA)'s archive of AIS data which has been used to generate information. Whilst AIS information provides an accurate representation of the received data, it is what 'is not' received that provides the greatest limitation. AIS-A provides characterization of commercial shipping (AIS-A) but misses the bulk of non-AIS vessels, including:

a) Commercial Vessels below $300 \mathrm{GT}$

b) Recreational Vessels

c) Fishing Vessels

d) Military/Government vessels whilst on deployment.

It is considered likely that a 40 nautical miles reception radius for AIS-A will be achieved by the (MCA) AIS network subject to various factors such as the power of the transmitted signal, the height of the transmitting ship's aerial and meteorological conditions. Poor reception could be as little as 20 nautical miles, or as much as 350 nautical miles for powerful transmissions during appropriate atmospheric conditions. AIS-B is a non-mandatory form of AIS typically used by small commercial craft, fishing vessels and recreational vessels. To prevent overloading of the available bandwidth, transmission power is restricted to 2 Watts, giving a range of up to 10 nautical miles. (Marine Management Organisation MMO, 2014)

\subsection{Related Research of AIS Usage}

AIS data in Traffic Separation Scheme (TSS) of Strait of Malacca and Singapore was used and produce a statistical include number of vessels, traffic density, and direction of traffic flow. A method to estimate the probability of collision from AIS data was presented to assess the collision risk (Olanrewaju, 2013).

In Traffic Route Measurements, the investigation is to illustrate the effort of traffic route measurement by comparison of various route version and to prognoses the validity of favored route proposals for expected traffic profile or density in future (Weintrit 2013).

A novel visualization model to appraise the maritime traffic situation based on ship's Automatic Identification System was proposed by Jiacai. The rate of ship turn, speed accuracy and ship encounter related to dangerous shipping area (Jiacai, Qingshan et al. 2012).

\section{Methodology}

\subsection{Equipments}

AIS receiver and antenna, AIS decoder and AIS analyzer or software are needed to analyze the data received by the AIS receiver. The antenna is set up at the higher place about 130 meter high facing the sea(Strait of Malacca) and port to receive better data coverage and the data are collected continuously in specific time frame within 5 days for the whole 24 hours.

\subsection{Data Processing Stages}

The processing stages involving of loading the AIS files in raw data format which are processed as discrete 'packages' of information. AIS receiver will received the report in ASCII data packet as a byte stream over serial or USB lines. By using the National Marine Electronics Association, NMEA 0183 or NMEA 2000 data formats and these data have been decoded to identify the vessel's Maritime Mobile Service Identity (MMSI), navigation status, rate of turn, speed over ground, true heading and time stamp. All the decoded data is saved in a comma separated values (CSV) file. Then, the file was analyzed using spreadsheet program.

\section{Result and Analysis}

The result was based on the data of AIS of Port Klang and Strait of Malacca in 5 days

\subsection{Mapping Traffic Density and Routes from AIS}

Figure 1 shows the traffic lanes of the Port Klang (region 1) and Strait of Malacca (region 2) were clearly denoted by high intensity use. The Port Klang is Malaysia's busiest shipping routes, situated at the north end of the Strait of Malacca. The total vessel transits at the Port Klang and Strait of Malacca was 105 in day 1 . The traffic was denser in region 2 at coordinate of $100.6^{\circ}$ to $101.2^{\circ}$ of longitude and $2.8^{\circ}$ to $3.2^{\circ}$ of 


\section{International Journal of Science and Research (IJSR) ISSN (Online): 2319-7064 \\ Index Copernicus Value (2013): 6.14 | Impact Factor (2014): 5.611}

latitude. The Strait of Malacca were more congested than Port Klang in day 1 and used as a gateway for many commercial vessels.

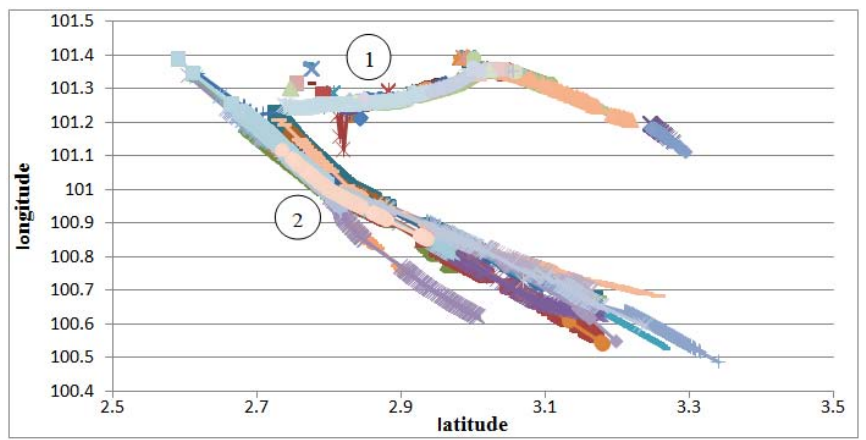

Figure 1: Vessels Path of Port Klang and Strait of Malacca in Day 1 (Monday, 9/2/2015)

Figure 2 show the total number of vessel pass through or anchored at Port Klang and Strait of Malacca was 99in day 2. The plotted path was more dense and congested in region 1 at coordinate of $101.0^{\circ}$ to $101.3^{\circ}$ of longitude and $2.6^{\circ}$ to $2.9^{\circ}$ of latitude.

Figure 3 shows the traffic density pattern with better data coverage in day 3. The traffic lanes of Port Klang and Strait of Malacca was visualise within the coordinate of $98.5^{\circ}$ to $101.5^{\circ}$ of longitude and $2.5^{\circ}$ to $4.8^{\circ}$ of latitude. The total number of vessel was the highest in day 3 where 159 vessels were recorded transit at Port Klang and Strait of Malacca. The traffic was denser in Strait of Malacca at coordinate of $98.6^{\circ}$ to $100.5^{\circ}$ of longitude and at $3.5^{\circ}$ to $4.8^{\circ}$ of latitude.

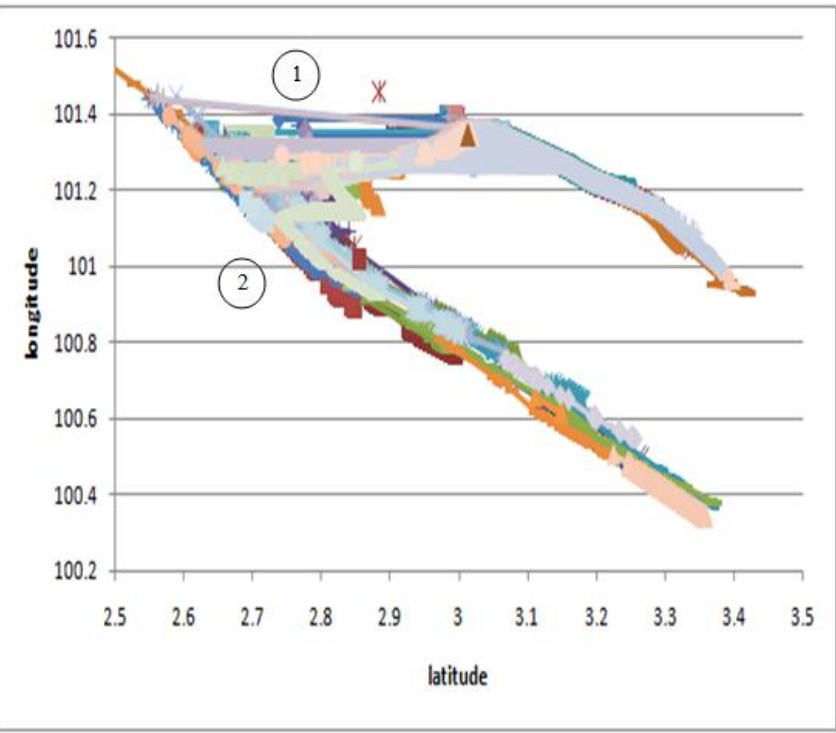

Figure 2: Vessels Path of Port Klang and Strait of Malacca in Day 2 (Tuesday, 10/2/2015)

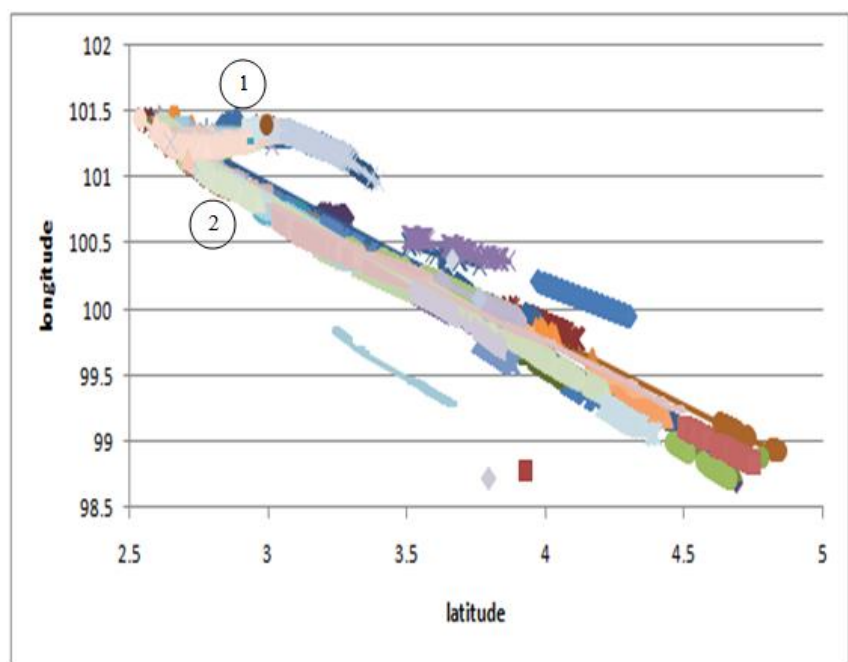

Figure 3: Vessels Path of Port Klang and Strait of Malacca in Day 3(Wednesday, 11/2/2015)

The Figure 4 show the pattern of traffic travelled or anchored by 125 vessels in day 4 . The traffic pattern and the area of congested path were quite similar with day 3 . The traffic was also denser in Strait of Malacca at coordinate of $99.0^{\circ}$ to $100.5^{\circ}$ of longitude and $3.5^{\circ}$ to $4.4^{\circ}$ of latitude.

Figure 5 show the lowest number of vessel travelled or anchored at Port Klang and Strait of Malacca recorded within 5 days. The pattern of traffic lanes of day 5 was different from the day 1 to day 4 where the traffic patterns do not show high intensity used of Strait of Malacca by commercial vessel. This was probably due to the weather effect. The reduction of intensity of the wave experienced along its path is known as attenuation. The attenuation is greater at the higher frequency and usually caused by the rain, fog, and dust. The total number of vessel was 94 in day 5 and the traffic lanes was denser in region 1 at coordinate of $101.0^{\circ}$ to $101.4^{\circ}$ of longitude and $2.6^{\circ}$ to $3.4^{\circ}$ of latitude.

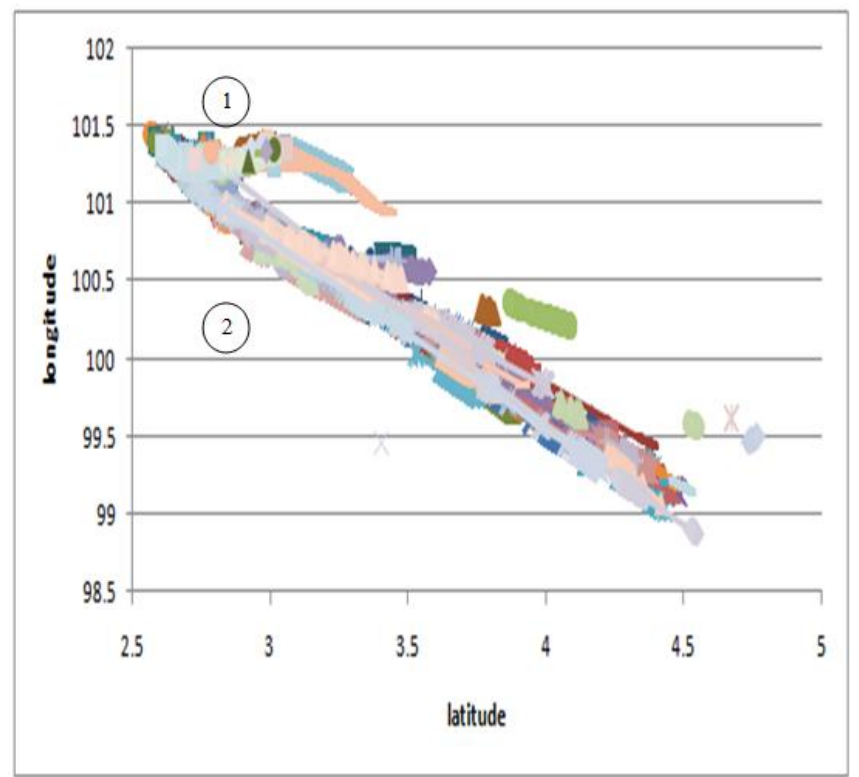

Figure 4: Vessels Path of Port Klang and Strait of Malacca in Day 4 (Thursday, 12/2/2015) 


\section{International Journal of Science and Research (IJSR) \\ ISSN (Online): 2319-7064}

Index Copernicus Value (2013): 6.14 $\mid$ Impact Factor (2014): 5.611

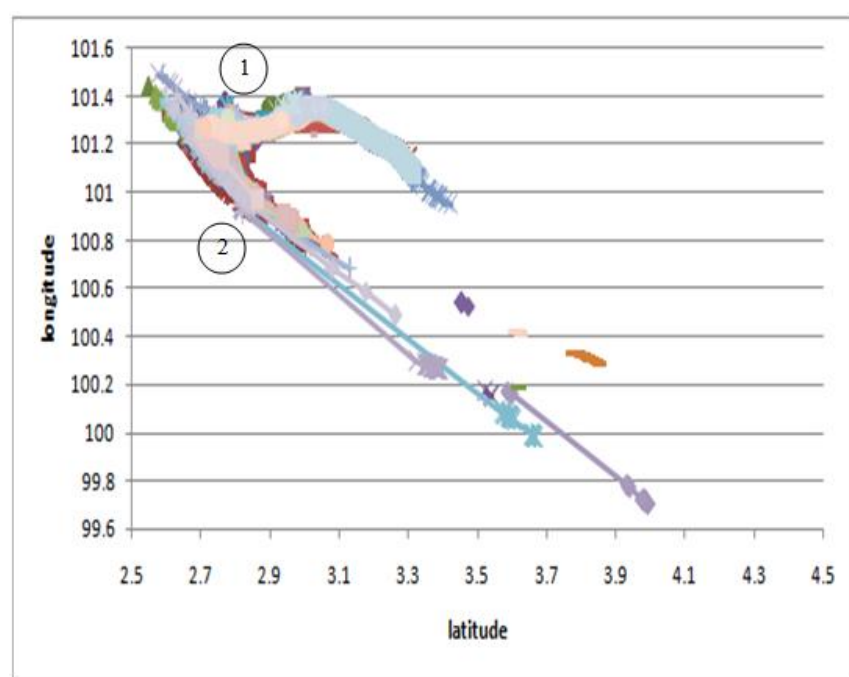

Figure 5: Vessels Path of Port Klang and Strait of Malacca in Day 5 (Friday, 13/2/2015)

Figure 6 shows the total number of vessels per day, from 9 February 2015 to 13 February 2015. From the statistic, the highest numbers of vessels recorded was 159 in day 3 . The second highest are 125 in day 4 followed by 105 vessels in day 1 . The lower number of vessels recorded was 99 in day 2 , followed by 94 vessels in day 5 . These values correspond to the number of vessel sailing at Port Klang and Strait of Malacca as in figure 2, 3, 4, 5 and 6.

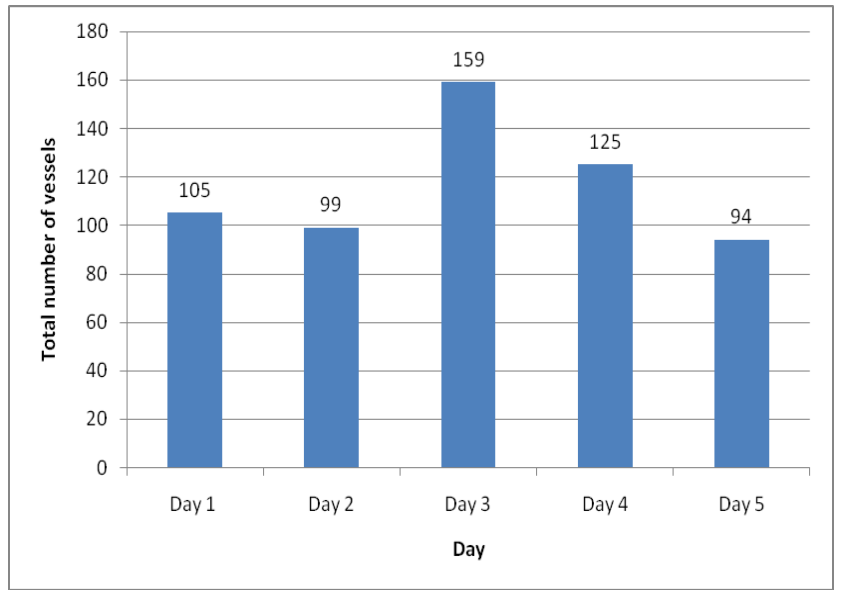

Figure 6: Total Number of Vessels within 5 Days

\section{Summary of Research}

From the data analyzed and from the vessel path mapping, shows that high density of traffic was along Strait of Malacca and also at Port Klang. Strait of Malacca is a narrow, $805 \mathrm{~km}$ (500 mile) stretch of water between Peninsular Malaysia and the Indonesian island of Sumatra. The strait is the main shipping channel between the Indian Ocean and the Pacific Ocean, linking major Asian economies such as India, China, Japan and South Korea.

\section{Conclusions and Recommendations}

This paper highlights how the Automatic Identification System (AIS) data can be used in the studies of high density of vessel traffic in busy waterways. In this context, AIS data of Port Klang and Strait of Malacca are collected to visualize the pattern of traffic density. AIS provide accurate real time data, which are valuable in traffic research and statistical analysis in busy waterways. As the future plan, this study also can be done in other port in Malaysia, such as Johor port, Kuantan port, Penang port and also other port from East Malaysia. There are at least 13 ports in Malaysia with their own capabilities and facilities to facilitate the large scale movement and delivery of goods. In addition, AIS system can continuously transmit a short message containing information of position, course over ground (COG), speed over ground (SOG), gyro course (heading) and others. Therefore, other information transmits by AIS can be analyze to gain more information about marine transportation as the growth in the industrial sector in Malaysia has leaded Malaysia as one of the most important nation in the global trade.

\section{References}

[1] Xiaobo Qua, Qiang Menga, Li Suyi (2011), "Ship collision risk assessment for the Singapore Strait". Journal of Accident Analysis and Prevention 43, 2030 2036

[2] Port Klang Authority. "Port Klang Malaysia Marine Information Handbook". Retrieved from http://www.pka.gov.my/phocadownload/marine_notice/ marine handbook 22015.pdf

[3] Jun Min Mou, Cees van der Tak, Han Ligteringen. "Study on collision avoidance in busy waterways by using AIS data", Ocean Engineering, Volume 37, Issues 5-6, April 2010, Pages 483-490

[4] Watagawa, M.; Kobayashi, E.; Wakabayashi, N., "Monitoring of vessel traffic using AIS data and ALOS satellite image," in OCEANS, 2012 - Yeosu, vol., no., pp.1-4, 21-24 May 2012

[5] Jiacai, P., Qingshan, J., Jinxing, H., \& Zheping, S. (2012). "An AIS data Visualization Model for Assessing Maritime Traffic Situation and its Applications". Procedia Engineering, 29(0), 365-369.

[6] Olanrewaju, O. S. (2013). "Marine Technology and Sustainable Development: Green Innovations

[7] Weintrit, A. (2013). Marine Navigation and Safety of Sea Transportation: Navigational Problems, Taylor \& Francis.

[8] Marine Management Organisation (MMO) (2014), "Mapping UK Shipping Density and Routes from AIS". A report prepared by ABP Marine Environmental Research Ltd, pp 35. 